\title{
Correction to: Radio and Radar Astronomy Projects for Beginners
}

\section{Steven Arnold}

\section{Correction to: \\ S. Arnold, Radio and Radar Astronomy Projects for Beginners, The Patrick Moore Practical Astronomy Series, https://doi.org/10.1007/978-3-030-54906-0}

The original version of this book was inadvertently published with few errors in Chapters 1, 2,7 and 9. This has now been updated in the mentioned chapters in this version.

The updated online versions of these chapters can be found at https://doi.org/10.1007/978-3-030-54906-0_1 https://doi.org/10.1007/978-3-030-54906-0_2 https://doi.org/10.1007/978-3-030-54906-0_7 https://doi.org/10.1007/978-3-030-54906-0_9

(C) The Editor(s) (if applicable) and The Author(s), under exclusive license to Springer Nature Switzerland AG 2021 S. Arnold, Radio and Radar Astronomy Projects for Beginners, The Patrick Moore Practical Astronomy Series, https://doi.org/10.1007/978-3-030-54906-0_20 